\title{
Letters
}

\section{Research bureaucracy in the United Kingdom}

\section{Seeking a balance: response from the Department of Health and COREC}

EDITOR-Several articles about research ethics committees in the issue of 31 July have been constructive in advising about the need for change. Others have been less helpful, especially when based on error or misconception.

Nicholson claimed that research ethics committees may be unable to function because of political control. There is not, and never has been, a proposal for "direct political control" of research ethics committee membership. The European Directive on Clinical Trials (directive 2001/20/EC) legally obliges all member states, including the United Kingdom, to "take the measures necessary for establishment and operation of ethics committees." The newly created United Kingdom Ethics Committee Authority simply comprises the four ministers of the

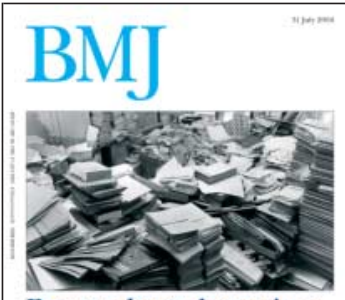

Researchers drowning in bureaucracy

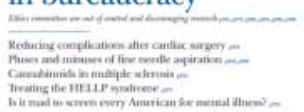

intelligent debate can only help. Ward et al offer a useful summary of the issues related to access to individuals and their data in epidemiological research. ${ }^{3}$ Their project would now require only one application as opposed to the 213 they had to make in 1998.

Jamrozik is initially critical of the new national application form. ${ }^{4}$ However, his ensuing well-crafted arguments make a good case for a comprehensive assessment of the researcher's understanding of the ethical issues in research. But, as he says, to submit an ideal application, researchers require thorough training in both the methods and the ethical issues relating to research in human subjects or their tissues or data.

His own experience as a research ethics committee member reveals how far we are from this ideal state, and the papers by Wald, and countries in the United Kingdom who have Jones and Bamford serve only to emphasise until now been separately responsible for their NHS research ethics committee systems. His claim that results of UK research could not now be used for regulatory purposes is simply unfounded.

Ethics committees must be independent of research organisations. This independence relates to their decisions, not their operating processes. Previously some 200 research ethics committees had different processes and forms - a researcher's nightmare. Any research now requires only a single ethical review, irrespective of the number of UK sites involved. All NHS research ethics committees in the United Kingdom increasingly operate in a standard fashion, providing an answer within 60 days. Repeated questions to researchers, which caused great delays, are not now permitted.

The five linked articles in the edition of 31 July nicely expose the dilemmas involved in ethical review of human research. What is ethically acceptable to society? How should research proposals be assessed against this? And how far can we go "at risk" in simplifying the assessment process? Parker et al address the first question, using rare diseases as a case study. ${ }^{2}$ Such projects often perplex ethics committees, and some informed and this. ${ }^{5}$ Wald could have saved himself a lot of time, effort, and phone calls if he had read the "question-specific guidance" published on the COREC web site (http:// corec.org.uk). It explains nearly all the questions, and often states what the ethics committee is looking for. He would have found descriptions and URLs for the two reference numbers (ISRCTN and EudraCT) for which he claims no guidance was given.

Many will disagree with his claim that most questions in Part A are not related to ethical review. Conflict of interest of the researcher, indemnity for the protection of participants, and confidentiality of data are widely accepted as core ethical issues. Part B is divided into sections specific to particular activities-for example, use of stored tissueand for nearly all research, substantial portions of the form are simply not activated, so it is normally far shorter than the maximum 57 pages. Part $\mathrm{C}$ assesses the suitability of the local investigator (such as qualifications and research experience) and the adequacy of site facilities. For clinical trials of medicines at least, the ethics committee is now legally obliged to consider them.
Part D was an attempt to be helpful to researchers by unifying the information required by research and development departments. Although now withdrawn, it may yet reappear if the UK research and development community can agree on a nationally acceptable dataset.

Many of the silent majority of several hundred other applicants who have successfully completed applications since the new form was introduced will doubtless have had some problems. However, sensible email enquiries, calls to the helpline, and reference to the question-specific guidance have worked for them. Our strong advice to applicants is to study the form and read the comprehensive advice early on when planning their research, reflect on the ethical requirements, and build them into their plans.

Seeking and updating informed consent is fundamental to good practice in research involving human participants. Jones and Bamford's failure to follow this suggests a need for the sort of training Jamrozik recommends. NHS and university employees have to be held to account for professionalism in research involving patients. It should come as no surprise if research managers intervene over undocumented changes in design or inaccurate consent forms.

No one pretends the current application form or the process is perfect, and it will be regularly reviewed. We welcome constructive criticism at this and any other time. If there is a reasoned case for omitting certain questions from the form or having a different, shorter, process for certain groups of applicants or low risk proposals (as has been suggested by some) then we would like to hear it.

John Pattison director of research and development Department of Health, London SW1A 2NS Sally.Bishop@doh.gsi.gov.uk

Terry Stacey director

Central Office of Research Ethics Committees, London W2 3QR

Competing interests: None declared.

1 Nicholson R. Another threat to research in the United Kingdom. BMJ 2004;328:1212-3. (31 July.)

2 Parker M, Ashcroft R, Wilkie AOM, Kent A. Ethical review of research into rare genetic disorders. $B M$ 2004:329:288-9. (31 July.)

3 Ward HJT, Cousens SN, Smith-Bathgate B, Leitch M, Everdemiological research in the UK general population. $B M J$ 2004.399:277-9. (31 July)

. seem to have lost? $B M J$ 2004:329.286 7 . (31 is the

5 Wald SD Bureaucracy of ethics applications, $B M J$ 2002

2002,329:282-4. (31 July ance. BMJ 2004;329:280-1. (31 July.) ington D, Will RG, Smith PG. Obstacles to conducting epi- 
Ethics committees have important roles in research

Editor-Jamrozik discusses the lost plot of research ethics paperwork in the issue of 31 July highlighting that ethics committees are out of control and discouraging research. NHS research ethics committees comprise volunteers who give up their time freely to mediate society's desire to protect potential research participants.

If anything can be learnt from recent high profile cases, such as those surrounding retention of organs for research, it is that society does not restrict its understanding of "harm" to purely physical damage. The focus of research ethics committees on information sheets for patients is driven not by a desire for "editorial control" but to ensure that potential participants are free to make fully informed decisions. Obscure and jargonistic text is not informative. Some frankly misleading information sheets that we review are apparently designed more to facilitate recruitment than inform the patient.

We agree that scope remains for improving the ethical review process, including the application forms. However, much of the difficulty experienced by researchers while completing the forms seems to derive from an incomplete understanding of the ethical issues around their research and often unclear boundaries between the research and its clinical setting. Patients have a right to know whether what they are subjected to in clinical practice (treatments or questionnaires) is for their clinical benefit or for research, or both.

It would be helpful to look beyond dissatisfaction with the current ethical review process expressed in the 31 July issue to a broader understanding of the purpose and value of ethical review to society. Research ethics committees work hard to facilitate not to obstruct research. We hope that the $B M J$ will publish a special issue in the near future dedicated to positive aspects of ethical review and research governance.

David A Walsh senior lecturer in rheumatology King's Mill Hospital, Mansfield Road,

Sutton-in-Ashfield, Nottinghamshire NG17 4JL david.walsh@nottingham.ac.uk

Michael Hewitt evaluation, audit and research manager Sherwood Forest Hospitals NHS Trust, King's Mill Hospital

Competing interests: DWA is chairman, North Nottinghamshire Local Research Ethics Committee.

1 Jamrozik K. Research ethics paperwork: what is the plot we seem to have lost? BMJ 2004;329:286-7. (31 July.)

\section{Good governance is needed}

EDITOR-Transparent ethical scrutiny should come sufficiently early in the "life" of a research project that the design can incorporate the management of any risks to the public. A feeding frenzy for funding opportunities can make it difficult to organise such early scrutiny. The BMJ shows examples of a new problem: the paralysis of research by bureaucracy associated with ethics committees. ${ }^{1}$ Even committee members seem helplessly entangled in the new proce- dures. ${ }^{2}$ Hopefully, your readers will help to loose the Gordian knot created by these central "COREC" procedures.

However, research governance goes far beyond the inefficiency of a particular committee and is unfairly caricatured by the "face" published here. ${ }^{3}$ At the heart of governance is accountability. ${ }^{4}$ The scientific community owes this accountability to the patients and wider public who support research activities. Without their trust and goodwill, academic medical research would die-or else, possibly, degenerate into the coercive horror of the Nazi doctors' "research" detailed at Nuremberg. At all stages of planning, implementing, and reporting research we have a duty to consider the safety and dignity of the participants, the relevance of research findings to clinical and public health improvements, and our openness to critical reflection and refinement of our work.

Learning to improve our governance of research is a crucial step to better research and wiser researchers. Professional bodies have an important role in promoting learning in a real context. ${ }^{5}$ What is the BMA doing to develop good governance?

Woody Caan professor of public healt

APU, Chelmsford, Essex CM1 1SQ

awc1@jess.che.apu.ac.uk

Competing interests: WC is involved in several research governance initiatives, beginning with facilitating a workshop on health and safety issues for NHS R\&D at the first research governance conference, London, 29 May 2001. His latest application to an NHS ethics committee, for an unfunded student project, bounced back last month, requiring a list of 20 changes (of which perhaps one is to do with ethics).

1 Wald DS. Bureaucracy of ethics applications. BMJ 2004;329:282-5. (31 July.)

2 Goodman NW. We have no control. Electronic response to: My last choice. bmj.com 2004. http://bmj.com/cgi/ My last choice. brij.com 2001. hip://bmj.com/cgi/

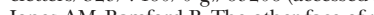
Jones AM, Bamford B. The other face of ance. BM 2004,329.280-1. (31 July.)

4 Caan W. Accountability a must. Times Higher Education Supplement 2004 March 5:19. Appleton J, Caan W. Guidance on research governance.

\section{Research governance is about protection,} not convenience

EDITOR-Jones and Bamford express surprise and frustration that their study was temporarily halted after they introduced an interview to the existing protocol without research ethics committee approval. ${ }^{1}$ They seem not to have recognised that introducing a new aspect to their project may bring additional ethical considerations and problems for their existing research aims.

They say that they did not mention this interview in the patient information sheets or consent forms, and they seem to have introduced it after data collection had begun. Whether the interview itself had ethical problems that required consideration is unclear, but that is why ethics committee approval is required before beginning a research project. In addition, their interview, however well meant, may have asked sensitive or inappropriate questions that might affect the validity of the data they were collecting.
This is not an issue of researchers accidentally filling in the wrong form or some other minor deviation. Jones and Bamford began what is in effect a new study without approval from the research ethics committee. Their intentions were no doubt good, and no harm may have ultimately resulted, but the ethics committee has a responsibility to assess research on ethical grounds before allowing it to proceed.

This article shows that research governance is, in fact, working well. Far from being an "over-reaction" that destroyed "the quality of the research," a potential breach of care for research subjects was identified and needed to be considered, just as a new project must be. More efficient and satisfying ways to resolve research governance issues may exist, but the primary concern of the research ethics committee must be to protect research participants. Any ethical implications related to loss of time and money to the researchers, although clearly frustrating, are secondary and should not cloud the issues.

Justin T Denholm hospital medical officer Austin Hospital, Heidelberg, VIC 3081, Australia neuromalacia@hotmail.com

Competing interests: None declared.

1 Jones AM, Bamford B. The other face of research governance. BMJ 2004;329:280-1. (31 July.)

\section{Time has come to face research}

\section{governance}

EDITOR-I am concerned that researchers such as Jones and Bamford believe that, having gained research ethics and trust approvals for their work, they are then free to change the protocol and the conduct of the study in whatever manner they choose to fit with any hypotheses that emerge as the research progresses.

Having recognised that the original proposal required these approvals before the research started, to ask patients personal questions about social contacts, relationships, family, and employment is clearly emotive. Judgments about whether these questions are acceptable in the context of the research should therefore be left to the ethics committees, not to individual researchers, to decide.

Other bodies, such as ethics and the governance team on behalf of the trust, must be aware of the exact nature of the intervention being applied to the participants, whether in the form of a questionnaire or a new drug. This article asserts that the actions of the trust's research office had a major effect on the study, when the effects were the result of the researchers not going through the correct procedures for protocol amendment.

Research governance was introduced to protect patients and ensures the transparent, safe, and fair conduct of research. These procedures must be acknowledged to be a compulsory part of the research process. Instead of arguing about their relevance, researchers and governance teams need to work together to ensure their smooth integration. 
Tracy M Elliott research manager

Sheffield Children's NHS Trust, Western Bank, Sheffield S10 2TH

tracy.elliott@sch.nhs.uk

Competing interests: None declared.

1 Jones AM, Bamford B. The other face of research governance. BMJ 2004:329:280-1. (31 July.)

\section{Practical example illustrates problems of} ethical review of genetics

EDITOR-Increasingly, genetic testing for newly discovered or recognised genes is only available in certain laboratories in the world. From 2000-3 I have on average each year submitted four full submissions and four "annex D" forms (these allow me to participate in someone else's medical research ethics committee proposal locally). Each full submission took four hours, and each annex D two hours. Most proposals allowed DNA analysis in a research study for clinical benefit as testing was not available in the NHS.

This year I have only been able to fill in one annex D equivalent-(the new "form C")-and one full proposal. Form C took eight to nine hours because, although it was partly completed by the lead researcher using "Form Filler v.2," my committee refused to accept anything other than v.3 (they eventually relented as a "one off" exception with a verbal warning). The full application related to six families with autosomal dominant renal cancer to send six DNA samples to a US researcher so that if renal cancer genes were isolated in the index cases, other family members could be screened for mutations, allowing 50\% of cases to be reassured and spared screening, and $50 \%$ to have targeted screening which would reassure if clear, or pick up cancers early and "save lives."

My committee required a full proposal, which took 19 hours to submit (eight months' calendar time, start to finish). The approved documentation was sent to the US committee, with a wait of four months before I could become an "accredited investigator" (all this so that I could not be sued for DNA theft, or closure of my or the US institution through penalty, etc, even though the families were keen for testing to be done). At the end of this year long process, I lost touch with one family, two index cases died, and the other three families are being asked consent with the long ethically approved consent form, having waited some time even on an urgent outpatient waiting list to be seen.

The last straw is the new consultant contract being introduced in our hospital. I am not supposed to be doing "research" during my NHS time. Parker et al and Jamrozik illustrate how new ethics committees will easily cope with their workload, as submissions from clinicians hoping to improve patient care will completely cease. ${ }^{12}$ Surely this is unethical?

Patrick Morrison consultant in clinical genetic Department of Medical Genetics, Belfast City Hospital Trust, Belfast BT9 7AB PatrickMorrison@bchn-i.nhs.uk
1 Parker M, Ashcroft R, Wilkie AOM, Kent A. Ethical review of research into rare genetic disorders. $B M$ of research into ra

Jamrork K Resear

thics paperwork: what is the plot we eem to have lost? BMJ 2004:329:286-7. (31 July.)

\section{Ask for help}

EDITOR-I recently took a similar length of time as Wald to complete a 60 page COREC form, for a study comparing two different approaches to the management of cancer pain. ${ }^{1}$ Wald may have been unduly harsh about the process and available support.

Perhaps I have been lucky, but I have had invaluable help from our trust's research and effectiveness department, based at the Bristol Royal Infirmary. Involving them at the protocol development stage undoubtedly facilitated this. I have also received useful (and money saving) advice from the Medicines and Healthcare Products Regulatory Agency and, like Wald, was able to apply for a doctors' and dentists' exemption, which was rolled over to a clinical trials authorisation on 1 May, thereby saving some $£ 2000$. Because other researchers were doing likewise (the agency's workload was quadrupled for that period; personal communication, 2004), this unsurprisingly resulted in some delay in issuing the certificates.

The COREC information technology helpline staff have been both helpful and friendly, even on the two occasions when it became clear that the technological problems I had in completing the form were due to my errors.

Wald refers to his difficulties with part A of the form, particularly the reference numbers requested. The COREC form website has documents with frequently asked questions and question specific advice, both highlighted when logging on to the system for the first time. These state clearly the nature of the reference numbers requested and what to do if they are not required or available for a study. I wonder if "resorting" to phoning local research and development offices and referring to available guidelines are the academic equivalent of asking for directions when lost?

Colette M Reid research fellow

Department of Palliative Medicine, Bristol

Haematology and Oncology Centre, Bristol BS2 8ED colette.reid@bristol.ac.uk

Competing interests: None declared.

1 Wald DS. Bureaucracy of ethics applications. $B M$ 2004;329:282-4. (31 July.)

\section{Editorial independence at the $B M J$}

NEJM editor says facts in letter are wrong and accusations reckless ...

EDITOR-In his letter on an editorial oversight committee for the BMJ Sackett makes patently false statements about the New England Journal of Medicine and the Massachusetts Medical Society. ${ }^{1}$ The society has never during my tenure or that of my predecessors suggested accepting or declining a paper for any reason, let alone a commercial one. The journal's editors have complete editorial independence.

The statements made by Sackett must be corrected to set the record straight; an apology is due to the journal and the Massachusetts Medical Society.

Jeffrey M Drazen editor in chief

New England Journal of Medicine, 860 Winter Street, Waltham, MA 02451-1413, USA

kpedersen@nejm.org

Competing interests: JMD is editor in chief of the New England Journal of Medicine.

Sackett DL. Editorial independence at the $B M J$. $B M J$ 2004:329:350. (7 August.)

...JAMA editor expresses disappointment at letter's smear...

EDITOR-I am deeply disappointed to read Sackett's smear of $J A M A,{ }^{1}$ especially in contrast with his invaluable support during and after a difficult, but ultimately invigorating, episode of JAMA's long and proud history of editorial independence.

Moreover, I am shocked that the $B M$ J would publish so baseless a defamation of $J A M A$, whose high regard has been so courageously earned. These assertions are particularly disappointing coming from a member of the $B M /$ s editorial board whose previous reputation has been to promote evidence in medicine.

In fact, despite Sackett's allegations, there has been no suppression of JAMA's papers or influence on editorial decisions by the American Medical Association (AMA) or by advertisers. The reputation of JAMA speaks for itself, as defined not only by the quality and quantity of manuscripts received but also by the high impact factor and worldwide readership. $J A M A$, the AMA, and the $B M /$ s readers deserve an explanation and an apology.

Catherine DeAngelis editor in chief

JAMA (Journal of the American Medical Association) 505 North State Street, Chicago, IL 60610, USA cathy_deangelis@jama-archives.org

Competing interests: CD is editor in chief of JAMA.

Sackett DL. Editorial independence at the $B M J . B M J$ 2004;329:350. (7 August.)

\section{... and the author apologises unreservedly}

EDITOR-In my zeal to protect editorial freedom at the $B M J$, and profoundly troubled over the fates of George Lundberg at JAMA and Jerome Kassirer at the New England Journal of Medicine, I shot from the hip in my original letter to the $B M J$.

In doing so I made a dumb mistake.

I lack evidence that parent societies and advertisers suppress the publication of articles they don't like at these journals.

I withdraw this assertion and apologise to DeAngelis and Drazen, their respective journals and medical societies, and everybody else for my error.

David L Sackett director

Trout Research and Education Centre at Irish Lake, RR 1, Markdale, ON, Canada N0C 1H0 sackett@bmts.com

Competing interests: See http://bmj. bmijournals.com/coi/content/full/324/7336

539/DC1. In addition, DS was the founding 
editor of Evidence-Based Medicine and sits on the advisory or editorial boards of ACP Journal Club, the BMJ, Clinical Trials, and the Journal of Clinical Epidemiology.

\section{Predicting bacterial cause in infectious conjunctivitis}

"History of conjunctivitis" needs clarifying EDITOR-The interesting and potentially valuable study reported by Rietveld et al discusses the prediction of the bacterial cause of infectious conjunctivitis. ${ }^{1}$ But can the authors please clarify what they mean by a "history of conjunctivitis"? Do they mean a history of conjunctivitis, recent injected conjunctivae, or what? What question were patients asked-surely they did not ask, "Do you have a history of conjunctivitis?" or its Dutch equivalent?

Anthony N Glaser private practice of family medicine Summerville, SC 29483, USA

tonyglaser@mindspring.com

Competing interests: None declared.

Rietveld RP, ter Riet G, Bindels PJE, Sloos JH, van Weert HCPM. Predicting bacterial cause in infectious conjunctivitis: cohort study on informativeness of combinations of signs and symptoms. BMJ 2004:329:206-10. (24 July.)

\section{Chlamydia needs to be taken into account}

EDITOR-In their paper on distinguishing bacterial conjunctivitis from other causes Rietveld et al omitted to mention chlamydial conjunctivitis as a possible cause for "sticky eyes" in adults. ${ }^{1}$ It was disappointing that detection of and screening for Chlamydia was not included in their laboratory protocol. A small but steady number of referrals to our sexual health clinic come from ophthalmologists screening for Chlamydia in adult conjunctivitis.

Although symptoms of chlamydial disease may be mild, it should be considered in the spectrum of clinical presentations likely in this study. A better understanding of prevalence of this condition within the cohort tested might have strengthened the paper.

Janette Clarke consultant physician in genitourinary medicine

Leeds General Infirmary, Leeds LS1 3EX

jan.clarke@leedsth.nhs.uk

Competing interests: None declared.

Rietveld RP, ter Riet G, Bindels PJE, Sloos JH, van Weert HCPM. Predicting bacterial cause in infectious conjunctivitis: cohort study on informativeness of combinations of signs and symptoms. BMJ 2004;329:206-10. (24 July.)

Three more questions for "conjunctivitis" may be important

EDITOR-It seems churlish to quibble with such an interesting study as that by Rietveld et al on predicting bacterial cause in infectious conjunctivitis, ${ }^{1}$ but aren't there more important questions?

How much harm do general practitioners do when they prescribe antibiotics? The real damage is done when keratitis is missed, the steroid often given with the antibiotic being the bigger culprit. Steroids will dampen the immune response, permitting resistant corneal pathogens to mushroom. In early keratitis this causes a notable delay in referral. Patients believe that they are better because the eye is less red-until vision drops. Detecting small corneal lesions without a slit lamp is all but impossible. A few pertinent questions may help prevent corneal scarring and visual loss.

The most useful are: "Do you wear contact lenses?" "Does your eye hurt, or does bright light hurt you?" "Is your vision worse?" If the answer to any of these is yes, don't prescribe, but refer. If you can't, give contact lens wearers an antibiotic that works for Pseudomonas-without steroids.

Anna Fierz ophthalmologist in private practice CH-8037 Zürich, Switzerland anna.fierz@medix-gruppenpraxis.ch Competing interests: None declared.

1 Rietveld RP, ter Riet G, Bindels PJE, Sloos JH, van Weer HCPM. Predicting bacterial cause in infectious conjunctivitis: cohort study on infor signs and symptoms. BMJ 2004;329:206-10. (24 July.)

Why say itching counts against bacterial infection in conjunctivitis?

EDITOR-The development of clinical rules that are easy to use to help discriminate between bacterial and culture negative acute conjunctivitis would be welcomed in primary care, but are the three simple questions proposed by Rietveld et al the right questions? ${ }^{1}$ One large problem is the use of itching to count against the likelihood of bacterial infection. Itching was present in 33 of 57 patients with positive culture results and was slightly more prevalent in those with negative cultures $(63 \%$ v $58 \%)$

Using itching to count for or against a diagnosis of bacterial conjunctivitis is wrong, as no significant difference is seen before and after logistic regression. I would not use the answer to this question to make treatment decisions on the basis of the data presented. A history of conjunctivitis seems helpful in a few patients, but this would not affect treatment choice in the majority. The best question seems to be, "Are both your eyes glued in the morning," with the biggest odds ratio after logistic regression analysis of 14.99 . I am puzzled by the odds ratio of 2.68 for one eye glued in the morning as the numbers of $53 \%$ culture positive and $62 \%$ culture negative would imply an odds ratio of below 1.0 .

The authors conclude that the assessment could possibly be done over the telephone, but in their exclusion criteria, ciliary redness is mentioned, and most doctors would be hard pressed to diagnose this over the telephone.

Richard L Davies general practitioner partner Glenlea Surgery, Stanningley, Pudsey LS28 6PE bleeprldavies@hotmail.com

Competing interests: None declared.

1 Rietveld RP, ter Riet G, Bindels PJE, Sloos JH, van Weer HCPM. Predicting bacterial cause in infectious conjunctivitis: cohort study on informativeness of signs and symptoms. BMJ 2004;329:206-10. (24 July.)

\section{Authors' reply}

EDITOR-Glaser asked for clarification of "history of conjunctivitis." We meant a self reported medical history. We asked patients if they had a history of allergic eye disease, prior infection of the eye with comparable symptoms, or other eye diseases.

We agree with Clarke that a conjunctivitis caused by Chlamydia can cause sticky eyes. A compromised immune system and an active sexually transmitted disease such as Chlamydia were exclusion criteria for our study. These conditions did not occur among the eligible patients.

Fierz's letter was mainly about steroids and keratitis. The issue of our study was an uncomplicated infectious conjunctivitis. Exclusion criteria were loss of vision, pain in the eye (eyeball), and wearing of contact lenses, all pertinent questions according to Fierz.

Davies would not use itching to make treatment decisions on the basis of our data. Still, itching fulfilled the criteria underlying our stepwise logistic regression approach. We entered variables whose association with a bacterial origin was fairly strong (univariate $\mathrm{P}$ value $\leq 0.1$ ) into the model. We then excluded variables when in a multivariable model their corresponding $\mathrm{P}$ value exceeded 0.15. In a logistic model the association between variables, or the contribution of a variable taking into account the other variables, counts. In line with the statistical literature on predictive models, this approach explicitly allows entry of variables whose $\mathrm{P}$ value exceeds 0.05 . In science, in exceptional cases only statistical significance is an issue. Our study was no such exception.

Davies was puzzled by the odds ratio of 2.68 for one glued eye. Davies thought that, according to the percentages in table 1 , the odds ratio would be below 1.0. However, "glued eyes" was a determinant containing three categories, modelled as two dummies. The correct numbers of true positives, false positives, false negatives, and true negatives o to calculate this odds ratio are $30,74,5$, and 33 , respec夜 tively.

We agree with Davies's comment on diagnosing ciliary redness over the telephone Doctors should be very careful when diagnosing over the telephone. This should probably have been emphasised more in our paper.

Remco P Rietveld general practitioner

R.P.Rietveld@amcuvan

Henk C P M van Weert general practitioner

Division of Clinical Methods and Public Health, Department of General Practice, Academic Medical Centre, University of Amsterdam, Meibergdreef 15, 1105 AZ, Amsterdam, Netherlands

Gerben ter Riet epidemiologist

Horten-Zentrum, Zürich, Switzerland

Competing interests: None declared. 


\section{Hospital chaplaincy units show bias towards Christianity}

EDitor-The Human Rights Act 1998 and the Patient's Charter place a legal responsibility on public bodies to ensure the rights of individuals to religious observance. ${ }^{12}$ Concern has, however, been expressed that access to spiritual care in hospitals for those of non-Christian faiths is limited. ${ }^{3}$ We therefore conducted a national survey of hospital chaplaincy units.

We randomly selected 100 NHS hospitals in England and Wales. Chaplaincy units were asked to complete a questionnaire, administered over the telephone, that inquired about worship space, chaplaincy staffing, and quality of care delivered to faith communities.

We established contact with 72 units, and all agreed to participate. Multifaith prayer rooms were reported to be present in 10 hospitals. Fifty four hospitals had a dedicated place of worship for Christians compared with four hospitals with a dedicated space for Buddhists, six for Hindus, four for Jews, 13 for Muslims, and five for Sikhs $(\mathrm{P}<0.001$ for all groups when compared with Christians). Fourteen hospitals had facilities for segregation of the sexes in prayer areas.

The hospitals in our sample employed 105 full time chaplains, of whom 98 were Christian $(\mathrm{P}<0.001$ for all faith groups compared with Christians). Sixteen units had written policies on ensuring that hospital chaplains received training in cultural diversity.

Overall quality of chaplaincy care available to patients and staff was considered by respondents to be significantly better for Christians than for all other faith groups $(\mathrm{P}<0.001)$.

Our findings show considerable disadvantage to non-Christians in relation to access to space for worship, chaplaincy staff, and quality of chaplaincy care. Some progress seems, however, evidenced by the recent guidance from the Department of Health on developing chaplaincy services that meet the needs of all faith communities. ${ }^{5}$

Aziz Sheikh professor of primary care research and development

Division of Community Health Sciences: General Practice Section, University of Edinburgh EH8 9DX aziz.sheikh@ed.ac.uk

Abdul Rashid Gatrad consultant paediatrician Department of Paediatrics, Manor Hospital, Walsall WS2 9PS

Usman Sheikh research assistan

Research and Documentation Committee, Muslim Council of Britain, London E15 1N

Sukhmeet Singh Panesar medical student

Imperial College London, London SW7 2AZ

Shuja Shafi consultant in public health

North West London Hospitals Trust, Harrow HA1 3UJ

Competing interests: AS, ARG, US, and SS are

Muslims and have (voluntary) positions with the

Muslim Council of Britain. SSP is a Sikh.

Human Rights Act 1998. www.hmso.gov.uk/acts/ acts 1998/19980042 htm (accessed 27 Aug 2004).

2 Department of Health. The patient's charter. London: DoH, 1999.

3 Sheikh A. Quiet room is needed in hospitals for prayer and reflection. $B M J$ 1997;315:1625.

4 National Statistics Online. UK census 2001. http:// www.statistics.gov.uk/census2001/defaultasp (accessed 27 Aug 2004).
5 Department of Health. $N H S$ chaplaincy:meeting the religious and spiritual needs of patients and staff. London: $\mathrm{DoH}, 2003$.

\section{All clinical trials must be reported in detail and made publicly available}

EDITOR-It is usually only the regulatory agencies, such as the Food and Drug Administration, that have access to clinical trials data submitted from pharmaceutical companies, as described by Lenzer for selective serotonin reuptake inhibitors in children. ${ }^{1}$ However, the situation is now different for paroxetine. Full reports of its clinical trials are available on the internet, ${ }^{2}$ and we can critically examine their data on childhood depression. Three unmistakable facts emerge.

Firstly, what the company calls "emotional lability" is none other than "suicidal tendencies." The reports did not label the symptoms "emotional lability" unless there was suicidality.

Secondly, two cases of suicidal tendencies were not counted towards "emotional lability." A 14 year old boy who "punched pictures, broke glass, and sustained lacerations that required six sutures," "expressed hopelessness and possible suicide thoughts," and "was hospitalized" was treated as a case of aggression but not of emotional lability. Another 11 year old boy who "threatened to harm himself and was hospitalized with an acute exacerbation" was counted as a case of exacerbated depression but not of emotional lability.

Thirdly, taking all these cases into account, the pooled odds ratio for suicidality with paroxetine was 2.77 (fixed effect model $95 \%$ confidence interval 1.03 to 7.41 ). No heterogeneity was present (figure).

There is one clear lesson to be learnt. All clinical trials, not only those conducted by drug companies but all of them, must be reported in detail and made publicly available as soon as reasonably possible. Without such policy internationally, neither healthcare professionals nor consumers can make sufficiently informed decisions.

Toshi A Furukawa professor

Department of Psychiatry, Nagoya City University Medical School, Mizuho-cho, Mizuho-ku, Nagoya 467-8601 Japan

furukawa@med.nagoya-cu.ac.jp

Competing interests: TAF has received research grants and fees for speaking from some pharmaceutical companies, which market antidepressants

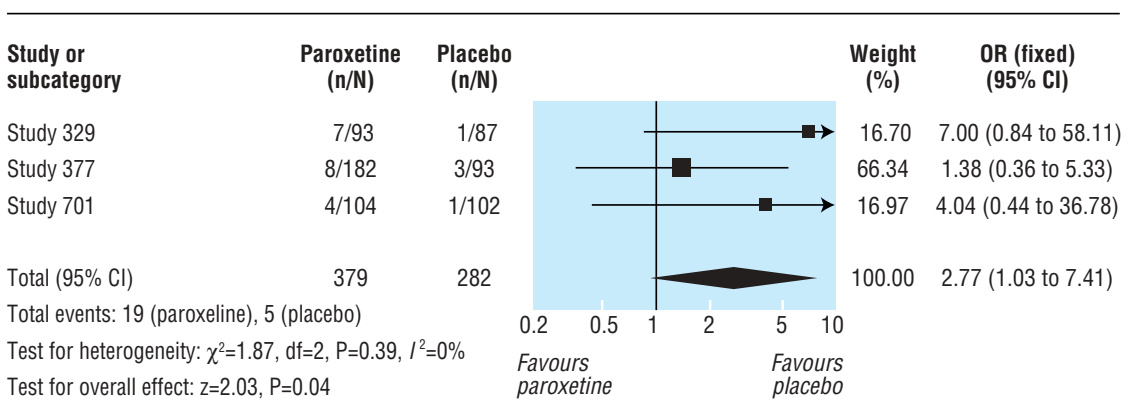

Suicidal tendencies in paroxetine trials with children and adolescents (paroxetine, fluvoxamine, milnacipran, trazodone, mianserin), antipsychotics (risperidone, olanzapine, quetiapine), nootropics (donepezil) and anxiolytics (loflazepate).

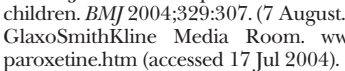

\section{Sing if you're glad to be sluts}

EDITOR-I read Farrell's Soundings column, on the good slut of general medicine admitting cases other disciplines would decline, with a mixture of pride and sadness. ${ }^{1}$ I felt enormous pride in the fact that the utilitarian nature of general medicine is recognised by our beleaguered colleagues in general practice. I was also particularly impressed with the recognition of the "game" we play when justifying such [social] admissions to each other, couching the awkward in the vaguest of terms so as not to offend one another.

But I also felt sadness. Sadness that as general physicians we don't celebrate and embrace our role as the "last refuge of the lost." It is time we ceased complaining about the unpredictable vagaries of a post-take ward round and rejoiced in our ability to deal with all the difficult conditions and situations that other hospital disciplines feel unable to cope with.

The serious point to be made is that, if some disciplines are "forced" to take patients who they would rather not, it probably follows that this may well affect the standard of care those patients receive. The passive acceptance with which general medicine takes all comers ironically means we simply get on with dealing with what we are given, quietly and with perhaps only a little complaint.

If I was optimistic I would hope that this article might herald the dawn of a new age of general medicine in which we are truly appreciated for what we are. In the absence of optimism I can at least consider that as general physicians we might be unsung heroes.

Say it loud: "I'm a slut and I'm proud."

Lewis G Morrison consultant physician in geriatric medicine

Roodlands Hospital, Haddington EH41 3PF

Lewis.Morrison@lpct.scot.nhs.uk

Competing interests: LGM is a general physician. 